\title{
EDITORIAL
}

\section{Oral care with chlorhexidine: beware!}

\author{
Lila Bouadma ${ }^{1,2^{*}}$ and Michael Klompas 3,4
}

๑ 2018 Springer-Verlag GmbH Germany, part of Springer Nature and ESICM

Pneumonia in hospitalized patients is usually induced by aspiration of oral pathogens into the lower respiratory system. Oral care with chlorhexidine for the prevention of pneumonia is an appealing alternative because it appears to be safe, effective, and less likely to select for antibiotic resistance than oropharyngeal or digestive decontamination $[1,2]$.

The evidence that chlorhexidine is safe and effective, however, may be less robust than it seems (Table 1). First, our perception that chlorhexidine oral care prevents ventilator-associated pneumonia (VAP) may be biased. While multiple meta-analyses of randomized controlled trials have reported lower VAP rates, this is not the case if one stratifies by blinding status [3]. Lower VAP rates are only present on meta-analysis of open label studies, not double-blind studies. This suggests a problem with ascertainment bias.

Second, chlorhexidine can have adverse effects on the oral mucosa. Plantiga and colleagues, for example, documented erosive oral lesions, ulcerations, white/yellow plaques, and bleeding mucosa in $9.8 \%$ of patients treated with $2 \%$ oral chlorhexidine [4]. Fortunately, these lesions disappeared after stopping chlorhexidine.

More disturbingly, two recent meta-analyses of randomized controlled trials and two observational studies have reported that oral chlorhexidine, paradoxically, may increase mortality risk [3, 5-7]. The mechanism leading to higher mortality rates is unclear, but it may be that some patients aspirate chlorhexidine and develop acute respiratory distress syndrome [8]. In addition, some patients may suffer allergic reactions, including anaphylaxis [9-11].

Finally, the presumption that oral care with chlorhexidine has no impact on resistance may be incorrect. Biocide and antibiotic efflux pump genes are present in bacteria and can confer resistance to chlorhexidine; widespread use of chlorhexidine may accelerate the spread of acquired resistance [12]. A recent study documented decreased susceptibility to chlorhexidine in a quarter of Escherichia coli isolates associated with pneumonia in ICU patients [13].

In an article recently published in Intensive Care Medicine, Deschepper et al. [14] add further concern that oral care with chlorhexidine may be harmful in some patients. These investigators performed a hospital-wide retrospective observational cohort analysis on the effects of chlorhexidine oral care on hospital mortality. They included 82,274 patients, of whom 11,138 (14\%) received chlorhexidine. Thee results showed that oral chlorhexidine was associated with an increased risk of death (OR 2.92; 95\% CI 2.62-3.26). The association was strongest in patients with the lowest baseline risk of death. The 


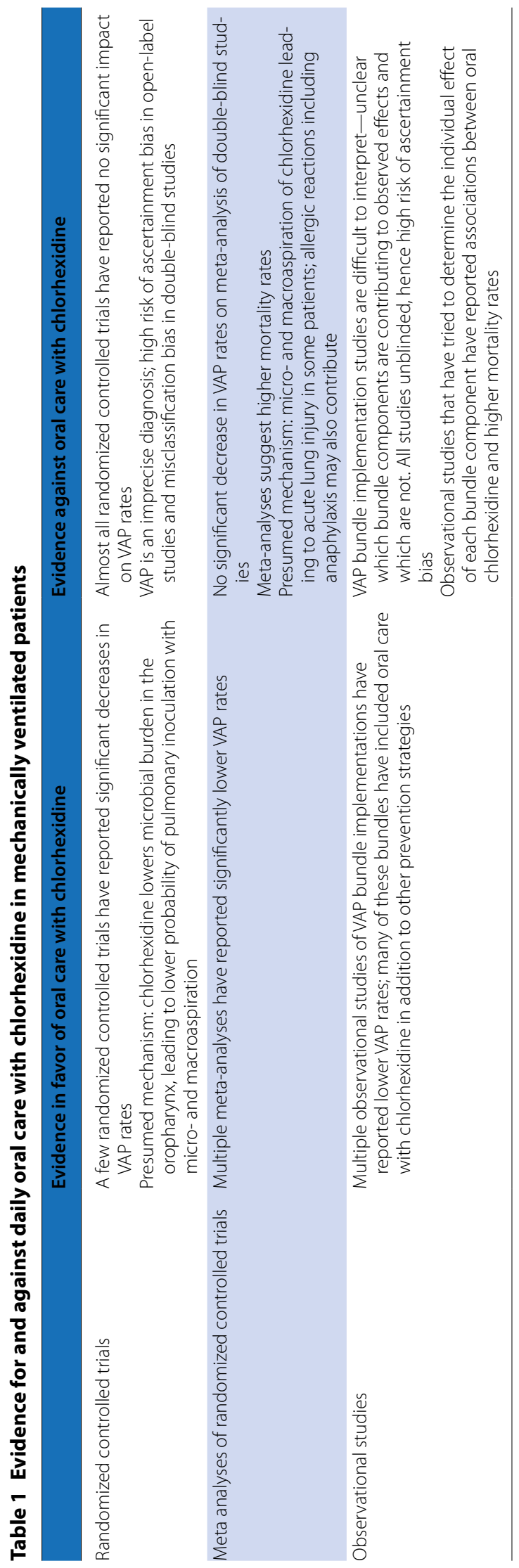

estimated number of patients needed to be exposed to result in one additional fatality was 47.1 (95\% CI $45.2-$ 49.1). In contrast to prior studies, however, the authors found no association between oral chlorhexidine and death in patients on mechanical ventilation or among cardiothoracic and vascular surgery patients.

The paper by Deschepper and colleagues extends the existing literature on possible harmful effects of oral chlorhexidine in ventilated patients to include non-ventilated patients outside the ICU as well. It is a provocative analysis that echoes a possible safety signal that has now been observed at least three times in three different studies [5-7]. Nonetheless, this study has important caveats that qualify its interpretation.

First and foremost, this was an observational, retrospective study. Less than $5 \%$ of non-ICU patients received chlorhexidine oral care, and the crude mortality for these patients was suspiciously high, at $13.5 \%$. The high mortality rate in the chlorhexidine-exposed population raises the strong possibility of confounding by indication (providers may be more likely to provide chlorhexidine oral care to sicker patients). Indeed, the authors noted that such treatment is often used in their hospital for dependent patients who cannot perform their own oral hygiene. The authors attempted to adjust for confounding by incorporating age, sex, emergency admission, medical or surgical admission, diagnostic category, and predicted risk of death into logistic regression models. They did not, however, include variables for dependency or any other indications for chlorhexidine. Likewise, the authors used All Patient Refined-Diagnosis Related Group (APR-DRG) codes to adjust for severity of illness [15]. These codes correlate with hospital mortality, but they lack the nuance of detailed clinical risk scores. Finally, the authors were not able to precisely quantify patients' exposure to chlorhexidine or demonstrate a dose-response relationship.

In contrast to previous work, the authors found no harmful effect of chlorhexidine in ventilated patients or cardiothoracic and vascular surgery patients. Indeed, the authors reported that chlorhexidine may lower mortality risk by almost $50 \%$ in patients ventilated for $<96 \mathrm{~h}$. This is difficult to believe given the large effect size relative to the low attributable mortality of VAP, the inconsistency of this finding with the rest of the study, and the strong possibility of survivor bias (nurses likely had more opportunities to use chlorhexidine in survivors versus those who died soon after intubation or who had care limitations placed due to impending death). Moreover, almost $90 \%$ of ventilated patients received chlorhexidine, thereby limiting the capacity to discern effects directly attributable to chlorhexidine in the ventilated population. 
So, should clinicians reconsider oral chlorhexidine for VAP/HAP prevention? A growing body of evidence, including the study by Deschepper and colleagues, suggests that indiscriminate use of chlorhexidine oral care may be harmful. Nonetheless, there are important gaps in our current knowledge: the signal is only present on meta-analysis and retrospective observational studies; some meta-analyses reach different conclusions, and the mechanism is uncertain [16]. For the present, however, given the lack of evidence of benefit in double-blind studies and multiple independent signals suggesting the possibility of harm, we believe we should follow the precautionary principle [17]. In our opinion, oral care with chlorhexidine should not be used to prevent pneumonia in non-ventilated or ventilated patients unless and until further data become available.

\section{Author details \\ 1 UMR 1137, IAME Team 5-DeScID: Decision Science in Infectious Diseases, Control and Care, INSERM/Université Paris Diderot, Sorbonne Paris Cité, Paris, France. ${ }^{2}$ Medical and Infectious Diseases ICU, Bichat-Claude-Bernard Hospital, Assistance Publique-Hôpitaux de Paris, Paris, France. ${ }^{3}$ Department of Population Medicine, Harvard Medical School and Harvard Pilgrim Health Care Institute, Boston, USA. ${ }^{4}$ Department of Medicine, Brigham and Women's Hospital, Boston, USA.}

Received: 19 April 2018 Accepted: 8 May 2018

Published online: 28 May 2018

\section{References}

1. Klompas M, Branson R, Eichenwald EC, Greene LR, Howell MD, Lee G, Magill SS, Maragakis LL, Priebe GP, Speck K, Yokoe DS, Berenholtz SM (2014) Strategies to prevent ventilator-associated pneumonia in acute care hospitals: 2014 update. Infect Control Hosp Epidemiol 35:915-936

2. Torres A, Niederman MS, Chastre J, Ewig S, Fernandez-Vandellos P, Hanberger H, Kollef M, Li Bassi G, Luna CM, Martin-Loeches I, Paiva JA, Read RC, Rigau D, Timsit JF, Welte T, Wunderink R (2017) International ERS/ESICM/ESCMID/ALAT guidelines for the management of hospitalacquired pneumonia and ventilator-associated pneumonia: Guidelines for the management of hospital-acquired pneumonia (HAP)/ventilatorassociated pneumonia (VAP) of the European Respiratory Society (ERS), European Society of Intensive Care Medicine (ESICM), European Society of Clinical Microbiology and Infectious Diseases (ESCMID) and Asociacion Latinoamericana del Torax (ALAT). Eur Respir J. https://doi. org/10.1183/13993003.00582-2017
3. Klompas M, Speck K, Howell MD, Greene LR, Berenholtz SM (2014) Reappraisal of routine oral care with chlorhexidine gluconate for patients receiving mechanical ventilation: systematic review and meta-analysis. JAMA Intern Med 174:751-761

4. Plantinga NL, Wittekamp BH, Leleu K, Depuydt P, Van den Abeele AM, Brun-Buisson C, Bonten MJ (2016) Oral mucosal adverse events with chlorhexidine 2\% mouthwash in ICU. Intensive Care Med 42:620-621

5. Price R, MacLennan G, Glen J (2014) Selective digestive or oropharyngeal decontamination and topical oropharyngeal chlorhexidine for prevention of death in general intensive care: systematic review and network meta-analysis. BMJ 348:g2197

6. Klompas M, Li L, Kleinman K, Szumita PM, Massaro AF (2016) Associations between ventilator bundle components and outcomes. JAMA Intern Med 176:1277-1283

7. Azevedo JR, Montenegro WS, Sousa CA, Silva MM, Leitao AL, Maranhao JP, Araujo RS (2017) Ventilator-associated events: prevalence, outcome, and preventability. Intensive Care Med Exp 5(Suppl 2):44

8. Klompas M (2017) Oropharyngeal decontamination with antiseptics to prevent ventilator-associated pneumonia: rethinking the benefits of chlorhexidine. Semin Respir Crit Care Med 38:381-390

9. Odedra KM, Farooque S (2014) Chlorhexidine: an unrecognised cause of anaphylaxis. Postgrad Med J 90:709-714

10. Garvey LH, Kroigaard M, Poulsen LK, Skov PS, Mosbech H, Venemalm L, Degerbeck F, Husum B (2007) lgE-mediated allergy to chlorhexidine. J Allergy Clin Immunol 120:409-415

11. Opstrup MS, Malling HJ, Kroigaard M, Mosbech H, Skov PS, Poulsen LK, Garvey LH (2014) Standardized testing with chlorhexidine in perioperative allergy - a large single-centre evaluation. Allergy 69:1390-1396

12. Kampf G (2016) Acquired resistance to chlorhexidine-is it time to establish an 'antiseptic stewardship' initiative? J Hosp Infect 94:213-227

13. La Combe B, Bleibtreu A, Messika J, Fernandes R, Clermont O, Branger C, Billard-Pomares T, Barnaud G, Magdoud F, Eveillard M, Kouatchet A, Lasocki S, Asfar P, Corvec S, Lakhal K, Armand-Lefevre L, Wolff M, Timsit JF, Bourdon S, Reignier J, Martin S, Fihman V, de Prost N, Bador J, Charles PE, Goret J, Boyer A, Wallet F, Jaillette E, Nseir S, Landraud L, Ruimy R, Danin PE, Dellamonica J, Cremniter J, Frat JP, Jaureguy F, Clec'h C, Decre D, Maury E, Dreyfuss D, Denamur E, Ricard JD (2018) Decreased susceptibility to chlorhexidine affects a quarter of Escherichia coli isolates responsible for pneumonia in ICU patients. Intensive Care Med 44(4):531-533

14. Deschepper M, Waegeman W, Eeckloo K, Vogelaers D, Blot S (2018) Effects of chlorhexidine gluconate oral care on hospital mortality. Intensive Care Med. https://doi.org/10.1007/s00134-018-5171-3

15. De Marco MF, Lorenzoni L, Addari P, Nante N (2002) Evaluation of the capacity of the APR-DRG classification system to predict hospital mortality. Epidemiol Prev 26:183-190

16. Hua F, Xie H, Worthington HV, Furness S, Zhang Q, Li C (2016) Oral hygiene care for critically ill patients to prevent ventilator-associated pneumonia. Cochrane Database Syst Rev 10:CD008367

17. Bouadma L, Karpanen T, Elliott T (2018) Chlorhexidine use in adult patients on ICU. Intensive Care Med. https://doi.org/10.1007/s0013 4-018-5137-5 